\title{
Óxido de grafeno (GO) funcionalizado adicionado ao encapsulante EVA para aplicação em módulos fotovoltaicos de silício cristalino
}

\author{
Functionalized Graphene oxide (GO) added \\ to EVA encapsulant for application in \\ crystalline silicon photovoltaic modules
}

\author{
Michele Cândida Carvalho de Oliveira ${ }^{1}$, Marcelo Machado Viana ${ }^{2}$, \\ Vanessa de Freitas Cunha Lins ${ }^{1}$
}

\footnotetext{
${ }^{1}$ Universidade Federal de Minas Gerais (UFMG). Departamento de Engenharia Química. Departamento de Engenharia Química. Av. Antônio Carlos, 6627 Prédio da Engenharia - Bloco 2 - 5 Andar, CEP: 31270-901, Campus da Pampulha, Belo Horizonte MG, Brasil.

${ }^{2}$ Universidade Federal de Minas Gerais (UFMG), Av. Antônio Carlos, 6627, Campus da Pampulha - Departamento de Química - sala 235 - Instituto de Ciências Exatas (ICEX), CEP: 31270-901, Belo Horizonte, MG, Brasil.

e-mail: michelecandida2004@yahoo.com.br, marcelomavi@yahoo.com.br, vlins@deq.ufmg.br
}

\section{RESUMO}

Os módulos fotovoltaicos, para serem economicamente viáveis, devem apresentar durabilidade de, no mínimo, 25 anos de operação. A fim de elevar a vida útil dos módulos, é necessário controlar a degradação do encapsulante, o copolímero de etileno acetato de vinila (EVA), pela ação da radiação ultravioleta (UV) e de outros elementos de intemperismo. Esse artigo tem como objetivo avaliar a aplicabilidade de nanocompósitos de EVA e óxido de grafeno (GO) funcionalizado com octadecilamina (ODA) como encapsulantes, caracterizando-os, antes e após terem sido submetidos a processos de envelhecimento acelerado, pelas técnicas analíticas: espectroscopia na região do infravermelho por transformada de Fourier (FTIR-ATR), análise termogravimétrica (TGA) e calorimetria exploratória diferencial (DSC). A fim de adquirir uma melhor dispersão do GO na matriz polimérica do encapsulante EVA, optou-se por sua funcionalização com octadecilamina. Os nanocompósitos preparados foram envelhecidos em câmara UVB, que é usualmente a radiação mais agressiva para polímeros. Os resultados da análise de FTIR-ATR indicam que a presença de GO incrementou a resistência à degradação do material. Foi também observada uma melhora nas propriedades térmicas dos filmes não envelhecidos, o que não foi observado nos envelhecidos. Conclui-se que a adição de GO trouxe benefícios quanto à resistência à degradação do material, embora a sua utilização em nanocompósitos para encapsulantes de célula fotovoltaica dependa do controle do número de folhas de grafeno o que modulará as propriedades ópticas e a transparência do encapsulante. $\mathrm{O}$ artigo apresenta uma contribuição para o avanço nas pesquisas referente à degradação, pela radiação UVB, do encapsulante EVA presente nos módulos fotovoltaicos de silício cristalino.

Palavras-chave: Degradação, encapsulante EVA, óxido de grafeno funcionalizado, módulos fotovoltaicos.

\section{ABSTRACT}

In order to be economically viable, photovoltaic modules must have durability of at least 25 years of operation. In order to increase the useful life of the modules, it is necessary to control the degradation of the encapsulant, the ethylene vinyl acetate copolymer (EVA), by the action of ultraviolet radiation (UV) and other elements of weathering. This article aims to evaluate the applicability of nanocomposites of EVA and graphene oxide (GO) functionalized with octadecylamine (ODA) as encapsulants, characterizing them, before and after the aging processes, by using the analytical techniques: spectroscopy in infrared region by Fourier transform (ATR-FTIR), thermogravimetric analysis (TGA) and differential scanning calorimetry (DSC). In order to acquire a better dispersion of GO in the polymeric matrix of the EVA encapsulant, we opted for its functionalization with octadecylamine. The prepared nanocomposites were aged in a UVB chamber, which is usually the most aggressive radiation for polymers. The results of the ATR-FTIR analysis indicated that the presence 
of GO increased the degradation resistance. An improvement in the thermal properties of unaged films was also observed, which was not observed in the aged ones. It is concluded that the addition of GO brought benefits regarding the resistance to material degradation, although its use in nanocomposites for photovoltaic cell encapsulants depends on the control of the number of graphene sheets, which will modulate the optical properties and the transparency of the encapsulant. The article presents a contribution to the advancement of research regarding the degradation, by UVB radiation, of the EVA encapsulant present in crystalline silicon photovoltaic modules.

Keywords: Degradation, EVA encapsulant, functionalized graphene oxide, photovoltaic modules.

\section{INTRODUÇÃO}

O desenvolvimento de módulos fotovoltaicos é alvo de diversas pesquisas e financiamentos em todo o mundo [1,2]. Para serem economicamente viáveis, eles precisam operar por 25 a 30 anos nas condições em que foram instalados [3].

Os filmes do copolímero de EVA utilizados como encapsulantes de módulos fotovoltaicos mostram-se eficazes por apresentarem propriedades adequadas e baixo custo e, assim, são amplamente utilizados. Entretanto, o efeito da degradação do encapsulante EVA pode ser significante durante a operação dos módulos, afetando a eficiência energética dos sistemas fotovoltaicos [4,5]. Dessa forma, o desenvolvimento de nanocompósitos de óxido de grafeno funcionalizado com o encapsulante EVA é uma alternativa para retardar o efeito da degradação, bem como melhorar suas propriedades [6].

O copolímero de EVA é um copolímero randômico (estatístico), representado na Figura 1 pode apresentar em sua estrutura blocos de vinte ou mais etilenos e diversas unidades do acetato de vinila. Sendo assim, conforme Oliveira e colaboradores [4], os mecanismos da degradação podem envolver as mesmas sequências para o polietileno e o poli(acetato de vinila) [4,5]

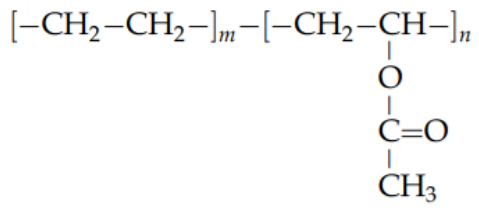

Figura 1: Estrutura química do copolímero de EVA.

Nandi e colaboradores [7] mostraram que nanocompósitos do encapsulante EVA com óxido de grafeno apresentam variações significativas nas propriedades do encapsulante EVA com pequenas quantidades adicionadas [7]. Em comparação ao encapsulante EVA puro, eles apresentam maior condutividade elétrica, maior resistência à degradação térmica e maior resistência mecânica [7].

Bahmanyar e colaboradores [8] prepararam filmes do nanocompósito EVA/GO via método de evaporação casting e várias propriedades deste material foram estudadas [8]. Os resultados mostraram que filmes dos nanocompósitos se mostraram impermeáveis, com boa estrutura morfológica e apresentaram melhoria mecânica. Estes filmes apresentaram potencial para uso em indústrias de embalagens.

Atendendo à existente demanda por encapsulantes mais resistentes à degradação ultravioleta, o objetivo deste artigo é preparar e avaliar a aplicabilidade de nanocompósitos EVA/GO (ODA) funcionalizado como encapsulantes em módulos fotovoltaicos de silício cristalino. Os nanocompósitos preparados foram caracterizados, antes e após terem sido submetidos a processos de envelhecimento acelerado (câmara UVB), pelas técnicas analíticas: espectroscopia na região do infravermelho por transformada de Fourier (FTIR-ATR), análise termogravimétrica (TGA) e calorimetria exploratória diferencial (DSC).

\section{MATERIAIS E MÉTODOS}

Inicialmente, adicionou-se $25 \mathrm{~mL}$ de água deionizada a $0,05 \mathrm{~g}$ de GO (15 a 20 folhas e 4 a $10 \%$ de oxidação nas bordas - Sigma Aldrich) e submeteu-se a mistura a agitação ultrassônica por 60 minutos. Preparou-se solução de 0,075 g de octadecilamina (ODA) (Sigma Aldrich) em 7,5 mL de etanol (Synth) e ambos, solução e dispersão, foram colocados num balão de três bocas em sistema de refluxo com agitação magnética intensa por 24 horas a $85^{\circ} \mathrm{C}$.

Em seguida a mistura foi filtrada e lavada com etanol. O produto foi secado na estufa por 24 horas a $60^{\circ} \mathrm{C}$. O material foi mantido em dessecador até sua utilização. 


\subsection{Preparação dos filmes}

Para cada filme pesou-se 1,325 g do encapsulante EVA [9], com teor aproximado de $33 \%$ de acetato de vinila e espessura $0,35 \mathrm{~mm}$ em um béquer, recortado em pequenos pedaços para melhor dissolução, e adicionou-se cerca de 50,00 mL de ciclohexano P.A. (Cinética Química). O sistema foi submetido à agitação magnética por aproximadamente 30 min até completa dissolução do copolímero em uma temperatura de aproximadamente $50^{\circ} \mathrm{C}$. Em outro béquer, adicionaram-se as massas necessárias de GO (15 a 20 folhas e 4 a $10 \%$ de oxidação nas bordas - Sigma-Aldrich) e GO funcionalizado para as diferentes concentrações de filme $(0,10$ e $0,25 \%$ em massa) e $10 \mathrm{~mL}$ de ciclohexano. $\mathrm{O}$ sistema foi submetido à agitação ultrassônica por 30 minutos em ultrassom de ponta, $20 \mathrm{kHz}, 20 \%$ de amplitude $(180 \mathrm{~W})$ com um ciclo intermitente de $60 \mathrm{~s}$ ligado e $30 \mathrm{~s}$ desligado.

Em seguida, misturou-se o conteúdo dos béqueres e o novo sistema foi submetido à agitação magnética por, aproximadamente, 30 minutos. As dispersões foram vertidas em placas de Petri e submetidas à secagem por evaporação pelo método casting.

\subsection{Envelhecimento dos filmes}

Amostras dos filmes preparados foram envelhecidas durante $200 \mathrm{~h}$ em uma câmara UV2000TM Fluorrescent UV/Condensation Weathering Device, da marca Atlas UV Condenser UC, que irradiava luz UVB $(\lambda=313$ $\mathrm{nm}$, a $\left.0,67 \mathrm{~W} / \mathrm{m}^{2}\right)$ em ciclos de $12 \mathrm{~h}\left(8 \mathrm{~h}\right.$ consecutivas de exposição à radiação UVB a $60 \pm 2^{\circ} \mathrm{C}$ e 4 horas consecutivas em umidade, sem luz, a $40 \pm 2^{\circ} \mathrm{C}$ ).

\subsection{Inspeção visual}

Os filmes preparados foram avaliados visualmente antes e após o envelhecimento acelerado, por meio de fotografias.

\subsection{Espectroscopia na região do infravermelho por transformada de Fourier}

Um espectrofotômetro FTIR da Thermo Fisher Scientific, modelo Nicolet 6700, no modo ATR, cristal de germânio, com 64 varreduras e resolução de $4 \mathrm{~cm}^{-1}$, foi utilizado para auxiliar na detecção de possível degradação nas amostras, por meio do aparecimento de bandas características nos espectros e pelo cálculo do índice de carbonila (IC).

O índices de carbonila, dado pela Equação 1, foi determinado a partir das razões entre o valor de absorbância (A) do modo vibracional de estiramento do grupo carbonil éster em $1735 \mathrm{~cm}^{-1}$ (vibração de estiramento $\mathrm{C}=\mathrm{O}$ de $-\mathrm{COO}-)$ e o modo vibracional simétrico de estiramento do metileno $\left(-\mathrm{CH}_{2}-\right) \mathrm{em} 2850 \mathrm{~cm}^{-1}$ $[5,6,10-12]$.

$$
I C=\frac{A_{1735}(\text { carbonil éster })}{A_{2850}(\text { metileno })}
$$

As regiões de interesse nos espectros FTIR-ATR de 2700 a $3100 \mathrm{~cm}^{-1}$ e de 1600 a $1850 \mathrm{~cm}^{-1}$ foram submetidas, por meio do Software OMNICTM, ao processo de deconvolução para separar possíveis bandas sobrepostas. As curvas foram ajustadas pela função matemática Lorentziana que se adequou melhor aos dados experimentais.

\subsection{Análise Termogravimétrica}

As análises termogravimétricas foram feitas em um equipamento da Shimadzu, modelo TGA-50. A termogravimetria foi empregada para avaliar a estabilidade térmica. Para os filmes preparados, o aquecimento partirá de aproximadamente $20^{\circ} \mathrm{C}$ até $600^{\circ} \mathrm{C}$, sob atmosfera de $\mathrm{N}_{2}$, razão aquecimento $=10^{\circ} \mathrm{C} /$ min e fluxo de 50 $\mathrm{mL} / \mathrm{min}$. Foram utilizados porta amostras de platina. Para a análise dos óxidos de grafeno, as mesmas condições experimentais foram empregadas, exceto a temperatura final do experimento, que será de $900^{\circ} \mathrm{C}$. A norma referência utilizada será a ASTM E1131 (Standard Test Method for Compositional Analysis by Thermogravimetry). 


\subsection{Calorimetria exploratória diferencial}

As análises de DSC foram realizadas utilizando um equipamento da Shimadzu, modelo DSC-60, com porta amostra de alumínio. As análises foram feitas com o intuito de verificar as temperaturas de transição de fase (Tm) e cristalinidade de cada amostra. As amostras foram submetidas a duas corridas nas mesmas condições. $\mathrm{O}$ equipamento foi programado, em cada corrida, para aquecimento de temperaturas próximas a $-30^{\circ} \mathrm{C}$ até $120^{\circ} \mathrm{C}$, a uma taxa de $10^{\circ} \mathrm{C} / \mathrm{min}$ em atmosfera de nitrogênio a uma vazão de $50 \mathrm{~mL} / \mathrm{min}$, com a massa das amostras variando entre 9 e $10 \mathrm{mg}$. A norma de referência utilizada será a ASTM D3418 (Standard Test Method for Transition Temperatures and Enthalpies of Fusion and Crystallization of Polymers by Differential Scanning Calorimetry). Para os cálculos do grau de cristalinidade, utilizou-se a Equação 2 e o valor de entalpia do polietileno puro $100 \%$ cristalino.

A temperatura e a entalpia de fusão foram avaliadas segundo a norma ISO 11357-3. A entalpia será calculada pela integral dos dois picos encontrados em torno de 40 e $70^{\circ} \mathrm{C}$. A cristalinidade será calculada segundo a Equação 2, A entalpia de fusão será calculada pela integral dos dois picos que apareceram entre aproximadamente $40^{\circ} \mathrm{C}$ e $80^{\circ} \mathrm{C}[5,6,13,14]$. A cristalinidade será obtida através da Equação 2:

$$
X c=\frac{\Delta \mathrm{H}_{f}}{\Delta \mathrm{H}_{f}^{*}} \mathrm{X} 100 \%
$$

Onde $X c=$ grau de cristalinidade; $\Delta \mathrm{H}_{\mathrm{f}}=$ entalpia de fusão obtida pela integral dos dois picos e específica de cada amostra e $\Delta \mathrm{H}_{\mathrm{f}}{ }_{\mathrm{f}}=$ entalpia de fusão do polietileno $100 \%$ cristalino $\left(\Delta \mathrm{H}_{\mathrm{f}}^{*}=293 \mathrm{~J} / \mathrm{g}\right)[3,5,6,15,16]$.

\section{RESULTADOS E DISCUSSÃO}

A Figura 2 apresenta os filmes de EVA/GO antes e após envelhecimento acelerado.

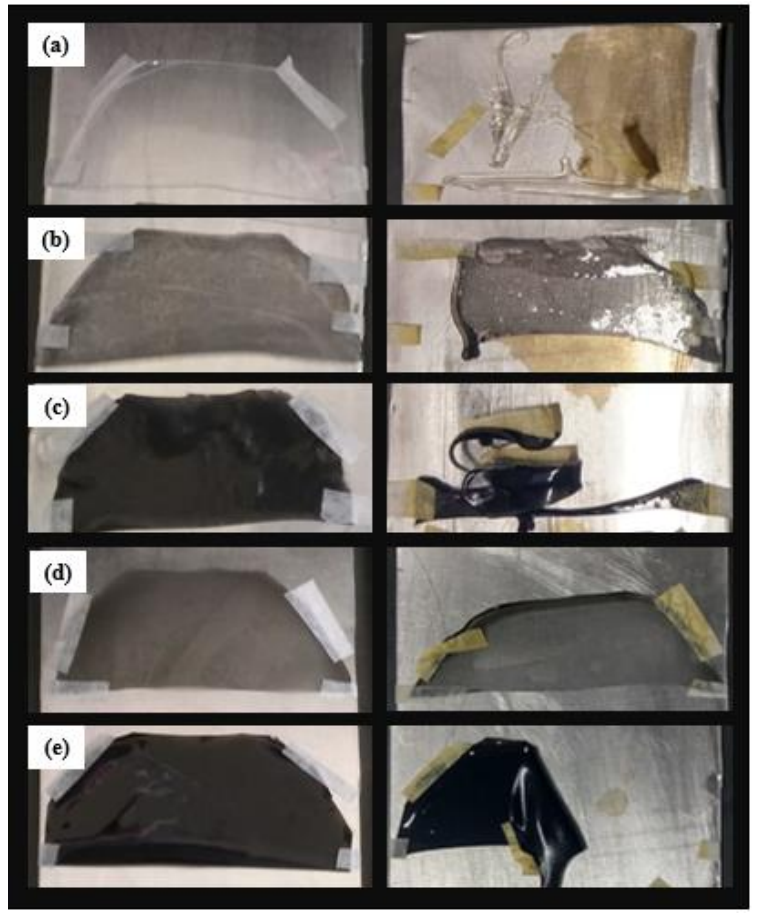

Figura 2: Imagem dos filmes do encapsulante EVA e EVA/GO não envelhecidos (à esquerda) e após o envelhecimento acelerado (à direita): (a) EVA, (b) $0,10 \% \mathrm{~m} / \mathrm{m} \mathrm{GO}$, (c) $0,25 \% \mathrm{~m} / \mathrm{m} \mathrm{GO}$, (d) $0,10 \% \mathrm{~m} / \mathrm{m} \mathrm{GO}$ funcionalizado, (e) $0,25 \%$ $\mathrm{m} / \mathrm{m}$ GO funcionalizado.

Após processo de envelhecimento acelerado, notou-se modificação na aparência dos filmes, evidenciando a degradação (Figura 2). Nota-se que o encapsulante EVA se apresentou bastante degradado. Aparentemente, o encapsulante EVA fundiu no processo de degradação, devido à temperatura da câmara de intemperismo. Os demais filmes, à exceção do filme com $0,25 \% \mathrm{~m} / \mathrm{m}$ de $\mathrm{GO}$, não aparentaram ter fundido. 
A dispersão do GO foi satisfatória tanto para os filmes preparados com o GO funcionalizado como para aqueles em que o GO não funcionalizado foi utilizado. A funcionalização pode ter auxiliado na melhor incorporação do óxido de grafeno na matriz polimérica. Para comprovar tal hipótese, técnicas analíticas que avaliam a superfície do material podem ser utilizadas.

Apesar de a funcionalização ter sido efetiva, como mostrado pela análise termogravimétrica, a melhor dispersão do GO ocorreu em todos os filmes preparados, devido à evaporação pelo método casting.

Apesar de o GO funcionalizado estar bem disperso, nota-se que os filmes permaneceram escuros, visualmente com baixa transparência, principalmente aqueles com maior concentração de GO funcionalizado. Tal aspecto do material pode inviabilizar sua utilização como encapsulante de módulos fotovoltaicos.

\subsection{FTIR-ATR}

Os espectros FTIR-ATR para as amostras não envelhecidas estão apresentados na Figura 3.

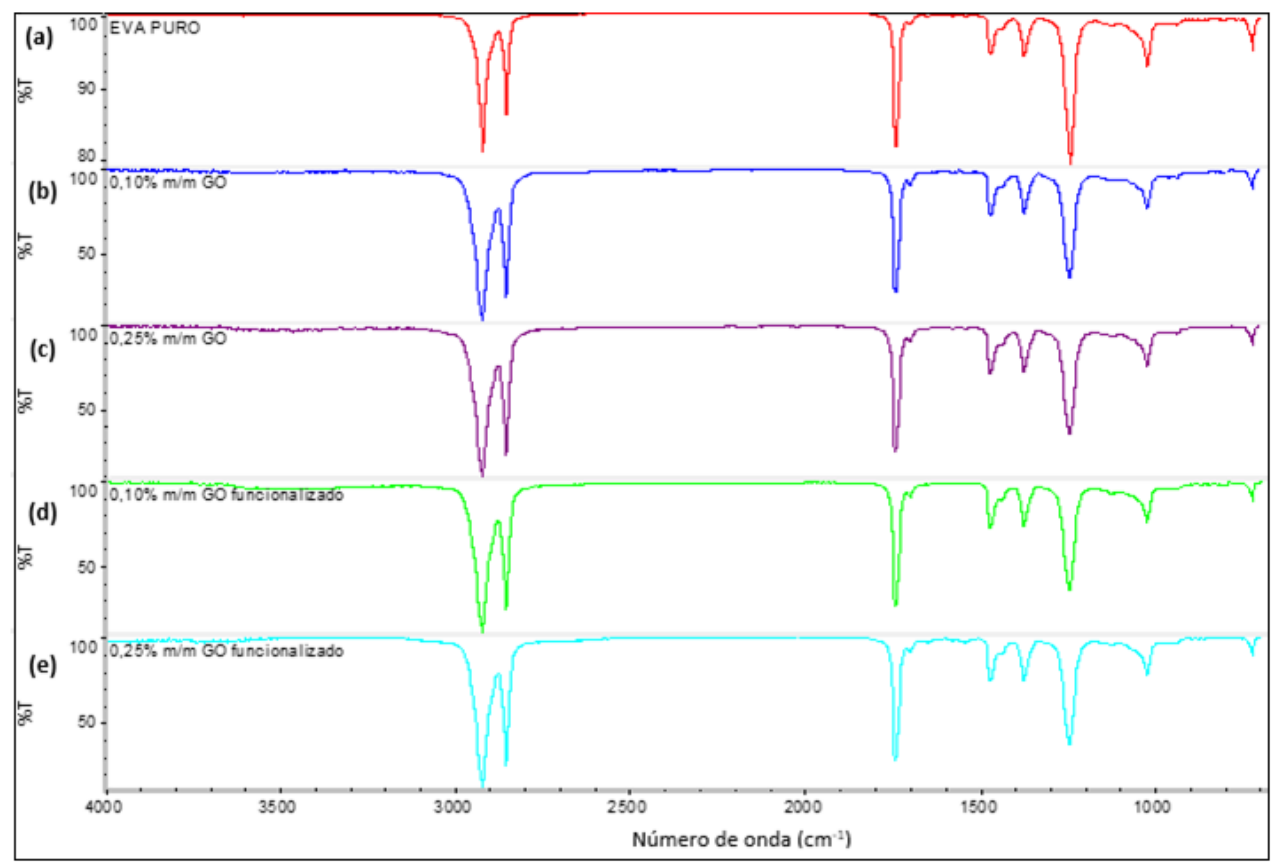

Figura 3: Espectros FTIR-ATR para as amostras não envelhecidas: a) encapsulante EVA; b) $0,10 \% \mathrm{~m} / \mathrm{m} \mathrm{GO}$; c) $0,25 \%$ $\mathrm{m} / \mathrm{m} \mathrm{GO}$; d) $0,10 \% \mathrm{~m} / \mathrm{m}$ GO funcionalizado; e) $0,25 \% \mathrm{~m} / \mathrm{m}$ GO funcionalizado.

Todas as bandas características do encapsulante EVA, listadas na Tabela 1, continuam presentes nos espectros acima apresentados.

Tabela 1: Bandas características do EVA e grupos funcionais correspondentes [6,11,12].

\begin{tabular}{c|c}
\hline NÚMERO DE ONDA $\left(\mathbf{c m}^{-1}\right)$ & DEFORMAÇÃo DO GRUPO FUNCIONAL \\
\hline 2917 e 2850 & Estiramento assimétrico e simétrico de $\mathrm{CH}_{2}$ \\
\hline 1735 & Estiramento de $\mathrm{C}=\mathrm{O}$ \\
\hline 1465 & Deformação assimétrica de $\mathrm{CH}_{2}$ \\
\hline 1371 & Dobra simétrica da vibração de $\mathrm{CH}_{3}$ \\
\hline 1237 e 1019 & Estiramento assimétrico de $\mathrm{C}-\mathrm{O}-\mathrm{C}$ \\
\hline 719 & Rocking interno da vibração de $-\mathrm{CH}_{2}-$ \\
\hline
\end{tabular}

As bandas características do óxido de grafeno, novamente, não apareceram. A presença da octadecilamina também não foi detectada nas amostras. Kuila e colaboradores [17] detectaram bandas referentes à ODA em $1634 \mathrm{~cm}^{-1}$, comprimento característico do estiramento de ligações duplas entre carbono e oxigênio 
de uma amida. Bandas em $1574 \mathrm{~cm}^{-1}$ também confirmaram a formação de ligações contendo nitrogênio, assim como bandas próximas a $3437 \mathrm{~cm}^{-1}$. Devido à baixa concentração, tanto do óxido de grafeno quanto da octadecilamina, nos filmes analisados, não foi possível detectar bandas características desses materiais por FTIR-ATR.

A Figura 4 apresenta a comparação dos espectros do filme do encapsulante EVA antes e após o envelhecimento acelerado.

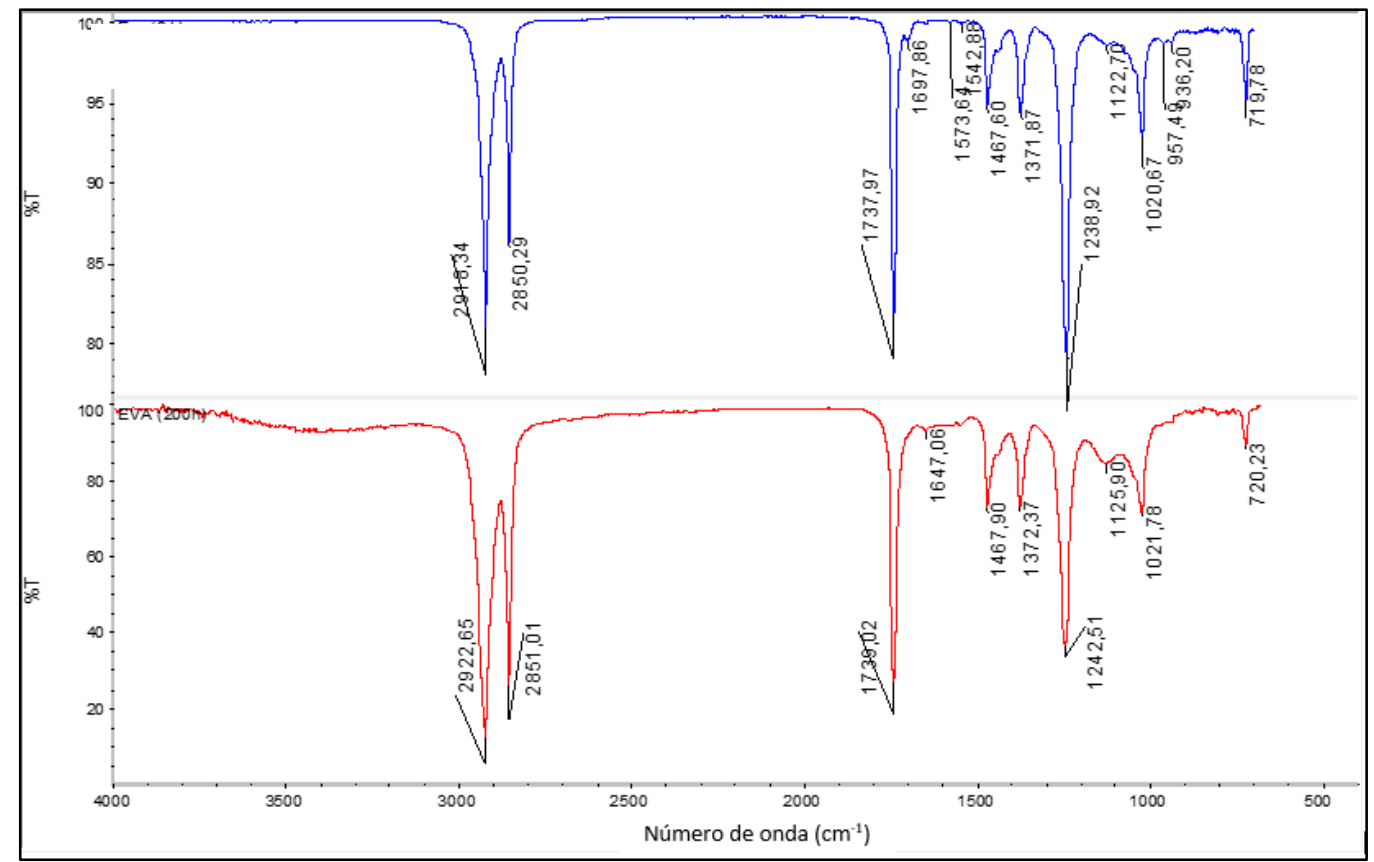

Figura 4: Espectros FTIR-ATR para o encapsulante EVA antes (em azul) e após envelhecimento acelerado (em vermelho).

Com o envelhecimento do material, notou-se o surgimento de uma banda larga próxima ao comprimento de onda $3400 \mathrm{~cm}^{-1}$, sendo indicativo do surgimento de hidroxilas, características da degradação do material $[5,6,18]$. Além disso, foi possível perceber uma alteração no aspecto do espectro da amostra envelhecida nos comprimentos de onda entre 1700 a $1600 \mathrm{~cm}^{-1}$. Tais alterações são indicativas de formação de produtos de degradação do encapsulante EVA, como o surgimento de cetonas e também de ligações duplas conjugadas, formadas no mecanismo de degradação do copolímero analisado [10,18]. Além disso, é perceptível alterações nos espectros nos comprimentos de onda entre 1200 a $1020 \mathrm{~cm}^{-1}$. Jin e colaboradores [10] observaram alterações nessa região em amostras do encapsulante EVA envelhecidas de forma acelerada, devido à presença de ésteres alifáticos e carbonila de cetona, produtos de degradação do encapsulante EVA [10].

A Figura 5 apresenta os espectros para a amostra com $0,10 \% \mathrm{~m} / \mathrm{m}$ de GO antes e após o envelhecimento acelerado. 


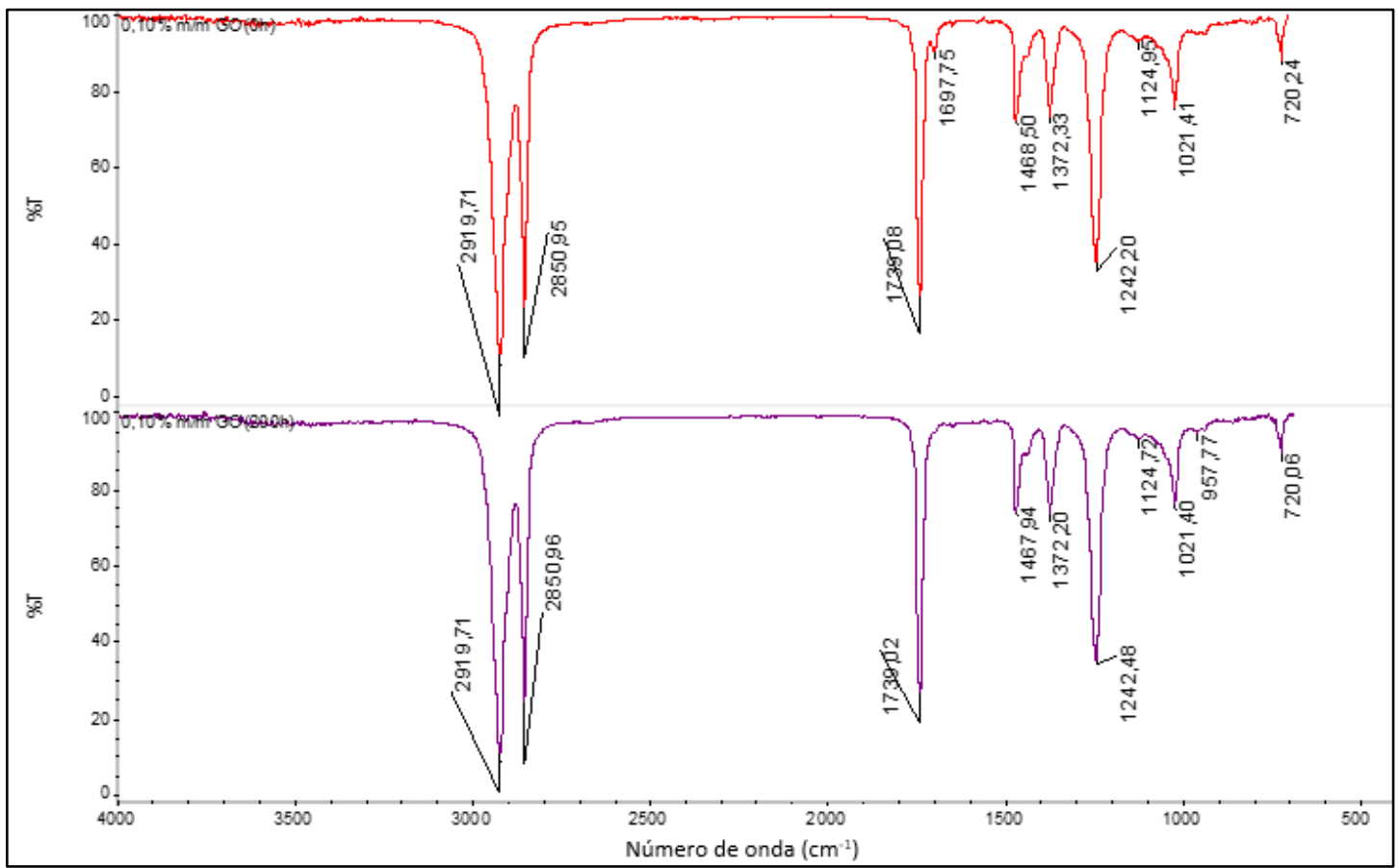

Figura 5: Espectros FTIR-ATR para a amostra com $0,10 \% \mathrm{~m} / \mathrm{m}$ de GO antes (em vermelho) e após o envelhecimento acelerado (em roxo).

A Figura 6 apresenta os espectros para a amostra com 0,10\% m/m de GO funcionalizado com octadecilamina antes e após o envelhecimento acelerado.

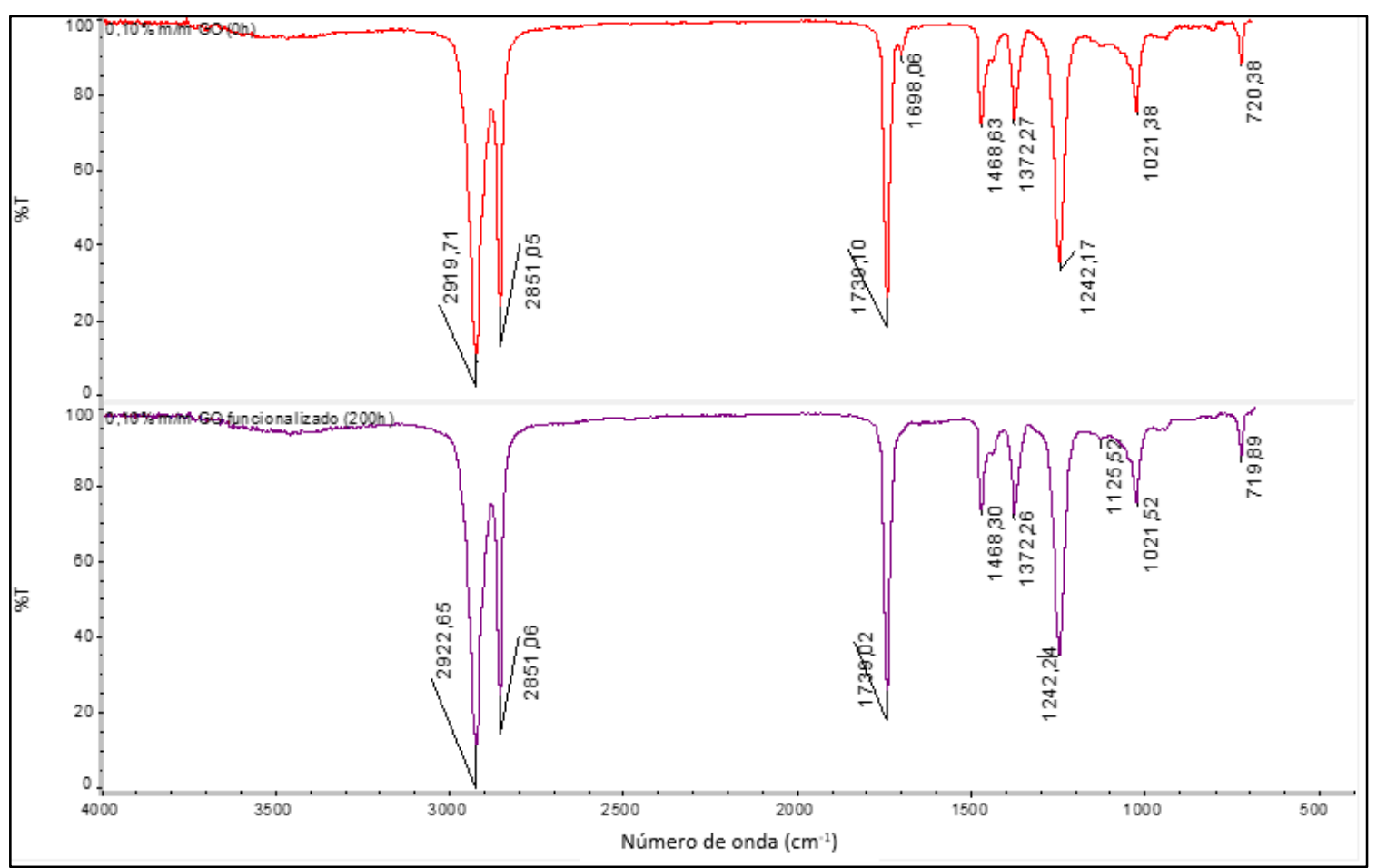

Figura 6: Espectros FTIR-ATR para a amostra com $0,10 \% \mathrm{~m} / \mathrm{m}$ de GO funcionalizado antes (em vermelho) e após o envelhecimento acelerado (em roxo)

As considerações feitas anteriormente para a amostra envelhecida do encapsulante EVA, como a mudança no aspecto de algumas regiões do espectro, não foram observadas de forma apreciável para as amostras contendo óxido de grafeno, sendo um indício que o processo degradativo dos filmes de nanocompósitos foi 
menos acentuado. Percebe-se que, na região próxima a $3400 \mathrm{~cm}^{-1}$, houve variação mais acentuada para a amostra contendo GO funcionalizado.

A Figura 7 apresenta os espectros para a amostra com $0,25 \% \mathrm{~m} / \mathrm{m}$ de $\mathrm{GO}$ antes e após o envelhecimento acelerado.

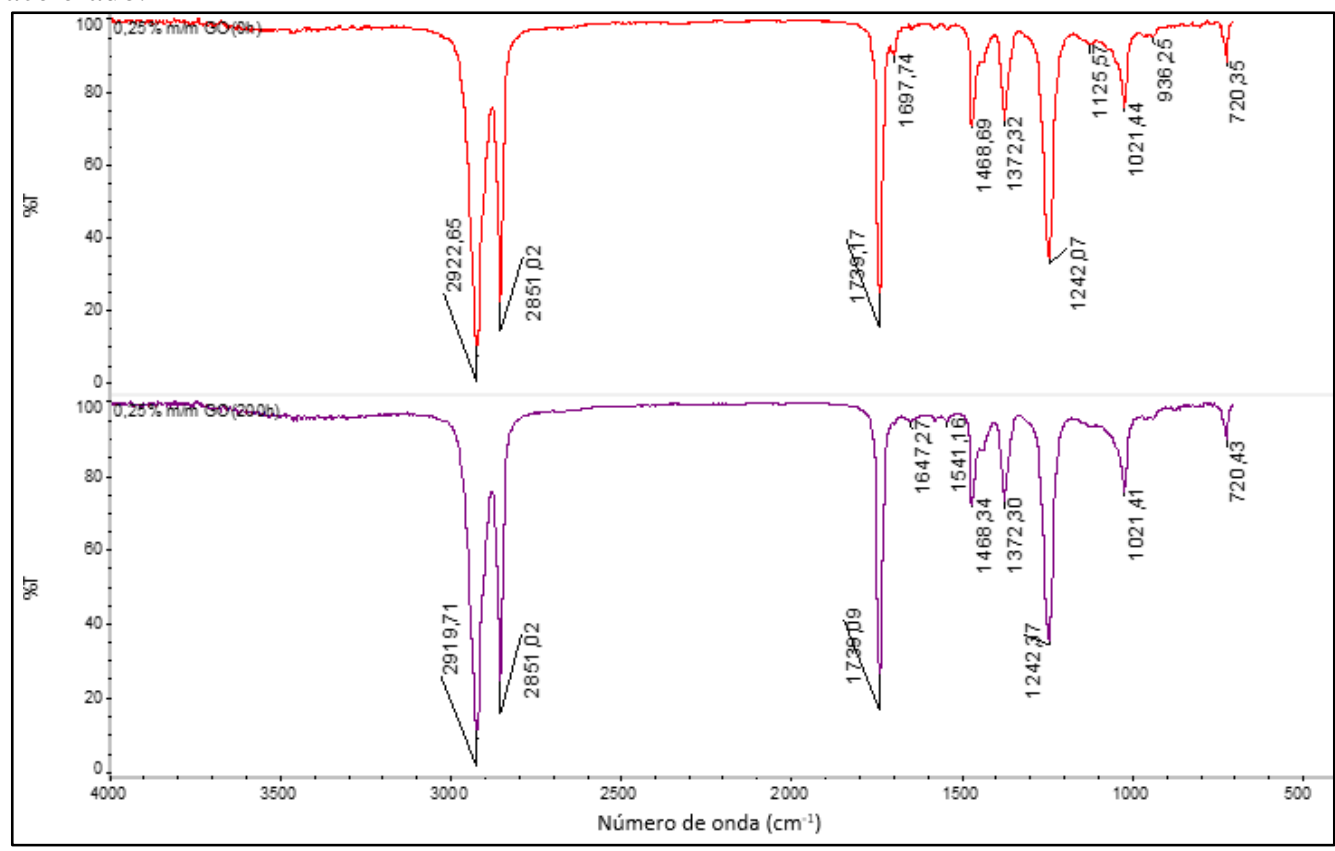

Figura 7: Espectros FTIR-ATR para a amostra com $0,25 \% \mathrm{~m} / \mathrm{m}$ de GO antes (em vermelho) e após o envelhecimento acelerado (em roxo).

A Figura 8 apresenta os espectros para a amostra com $0,25 \% \mathrm{~m} / \mathrm{m}$ de GO funcionalizado antes e após o envelhecimento acelerado.

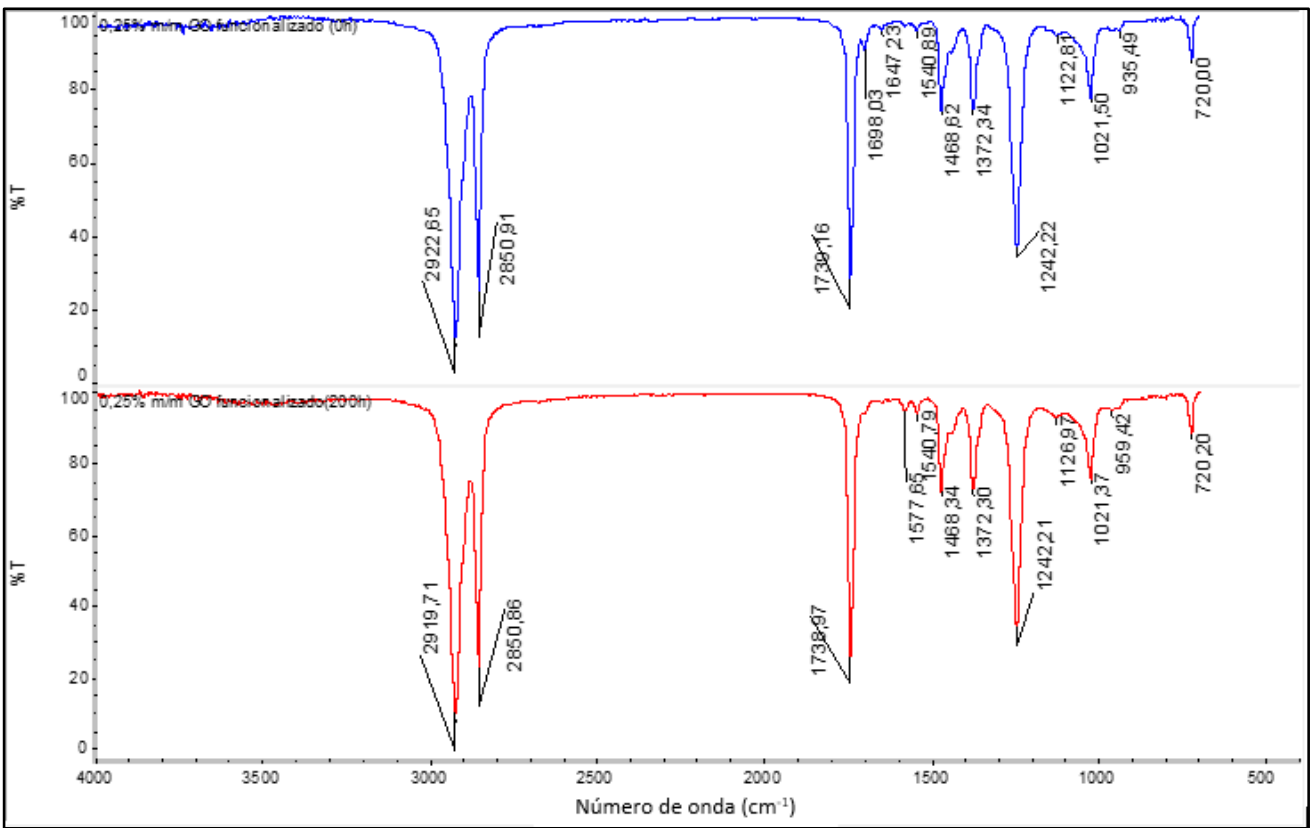

Figura 8: Espectros FTIR-ATR para a amostra com $0,25 \% \mathrm{~m} / \mathrm{m}$ de GO funcionalizado antes (em azul) e após o envelhecimento acelerado (em vermelho).

A Tabela 2 apresenta os valores dos índices de carbonila calculados para as amostras não envelhecidas e envelhecidas. 
Tabela 2: Índices de carbonila calculados para as amostras não envelhecidas e envelhecidas.

\begin{tabular}{c|c|c}
\cline { 2 - 3 } & \multicolumn{2}{c}{ ÍNDICE DE CARBONILA $\boldsymbol{A}_{\mathbf{1 7 3 5}} / \boldsymbol{A}_{\mathbf{2 8 5 0}}$} \\
\hline AMOSTRA & NÃO ENVELHECIDA & ENVELHECIDA \\
\hline EVA & 0,9 & 1,1 \\
\hline $0,10 \% \mathrm{~m} / \mathrm{m}$ GO & 1,0 & 1,0 \\
\hline $0,25 \% \mathrm{~m} / \mathrm{m}$ GO & 1,0 & 1,0 \\
\hline $0,10 \% \mathrm{~m} / \mathrm{m}$ GO func. & 1,0 & 1,0 \\
\hline $0,25 \% \mathrm{~m} / \mathrm{m}$ GO func. & 1,0 & 1,0 \\
\hline
\end{tabular}

Nota-se que apenas a amostra do encapsulante EVA sem adição de GO sofreu aumento nos índices de carbonila (de 22,2\%), indicando formação considerável de produtos de degradação nesse caso. Isto condiz com o crescimento da banda de $3400 \mathrm{~cm}^{-1}$ observado nos espectros dessa amostra envelhecida, como ressaltado anteriormente. Além disto, os índices de carbonila não se alteraram entre amostras não envelhecidas e envelhecidas para todas as concentrações e tipos de GO, indicando que, nesses filmes, não houve degradação apreciável do copolímero.

Portanto, percebe-se que o GO teve um efeito positivo quanto ao processo de degradação do encapsulante EVA, protegendo o copolímero. É importante ressaltar que o fator proteção que o óxido de grafeno conferiu ao encapsulante EVA não foi influenciado pela concentração e nem pelo tipo de GO (funcionalizado com octadecilamina ou não funcionalizado), já que os índices de carbonila dessas amostras se mantiveram todos constantes.

\subsection{TGA}

O efeito da funcionalização do GO pode ser percebido pelas curvas termogravimétricas desse composto antes e depois do tratamento com a octadecilamina, conforme mostrado na Figura 9.

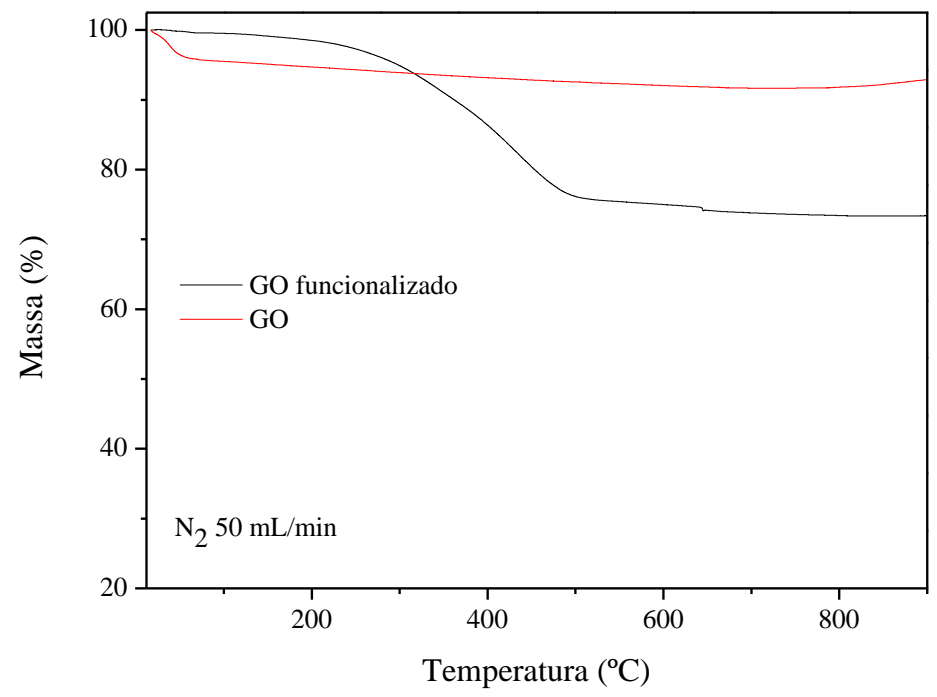

Figura 9: Curvas termogravimétricas do óxido de grafeno antes e após a funcionalização.

Pela curva termogravimétrica do GO antes da funcionalização é possível perceber, em $34,4^{\circ} \mathrm{C}$, um evento de perda de massa discreta, de cerca de 7,1\%. Essa ocorrência está relacionada ao desprendimento de moléculas de água adsorvidas na superfície do GO, conforme Maraschin [19], e é condizente com o padrão do GO altamente reduzido apresentado por Assal e colaboradores [20]. 
Após a funcionalização, a perda de massa ocorreu em $428,0^{\circ} \mathrm{C}$ e foi de, aproximadamente, $25,3 \%$. Esse comportamento está de acordo com a TGA do óxido de grafeno funcionalizado com ODA e é justificado pela decomposição das moléculas da octadecilamina, que ocorre entre 125 e $550^{\circ} \mathrm{C}$ [21]. Os resultados da análise termogravimétrica comprovam que a metodologia utilizada foi eficaz e que, de fato, o óxido de grafeno foi funcionalizado.

Na Figura 10 estão apresentadas as curvas dos filmes não envelhecidos e na Figura 11 as curvas das amostras envelhecidas.

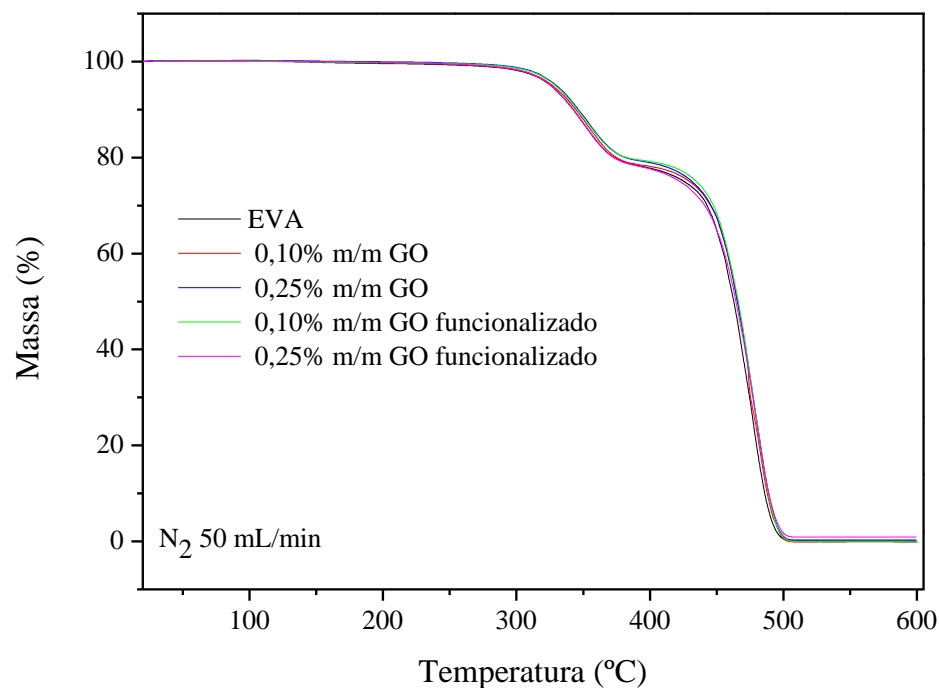

Figura 10: Comparação das curvas termogravimétricas das amostras não envelhecidas.

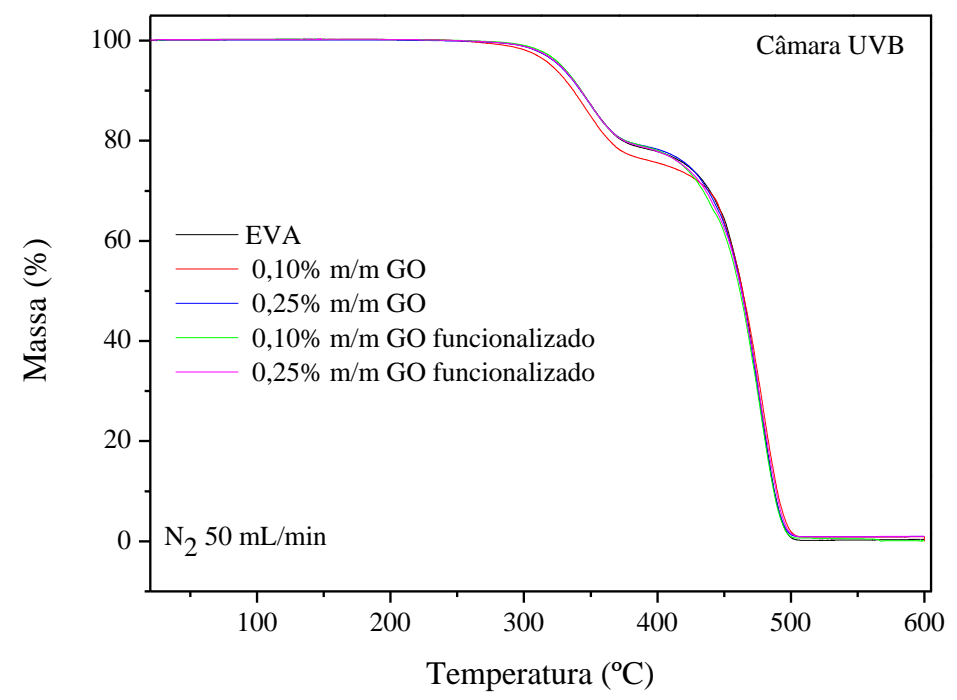

Figura 11: Comparação das curvas termogravimétricas das amostras envelhecidas.

As curvas obtidas para as amostras apresentaram aspecto similar, mostrando as duas etapas características do processo de degradação térmica do encapsulante EVA, em que aproximadamente $20 \%$ da massa é perdida no primeiro evento térmico e o restante no segundo. Para melhor visualização das temperaturas de degradação máxima das amostras, os dados foram compilados na Tabela 3. 
Tabela 3: Temperaturas de degradação máxima das amostras antes e após envelhecimento acelerado (UVB).

TEMPERATURA DE DEGRADAÇÃO MÁXIMA (ํㅡ)

\begin{tabular}{c|c|c}
\hline AMOSTRA & 1 PERDA DE MASSA & 2 PERDA DE MASSA \\
\hline EVA & 347,4 & 474,3 \\
\hline $0,10 \% \mathrm{~m} / \mathrm{m}$ GO & 360,4 & 472,4 \\
\hline $0,25 \% \mathrm{~m} / \mathrm{m}$ GO & 354,4 & 478,8 \\
\hline $0,10 \% \mathrm{~m} / \mathrm{m}$ GO func. & 352,2 & 479,3 \\
\hline $0,25 \% \mathrm{~m} / \mathrm{m}$ GO func. & 352,4 & 479,6 \\
\hline EVA (UVB) & 347,5 & 477,5 \\
\hline $0,10 \% \mathrm{~m} / \mathrm{m}$ GO (UVB) & 349,8 & 479,4 \\
\hline $0,25 \% \mathrm{~m} / \mathrm{m}$ GO (UVB) & 342,5 & 477,1 \\
\hline $0,10 \% \mathrm{~m} / \mathrm{m}$ GO func. (UVB) & 347,6 & 477,7 \\
\hline $0,25 \% \mathrm{~m} / \mathrm{m}$ GO func. (UVB) & 345,1 & 477,2 \\
\hline
\end{tabular}

A adição do GO ao encapsulante EVA nas concentrações de $0,10 \%$ e $0,25 \%$ promoveu um retardamento de $13,0^{\circ} \mathrm{C}$ e $7,0^{\circ} \mathrm{C}$, respectivamente, na temperatura máxima da primeira etapa de degradação do filme, que corresponde à degradação do acetato de vinila. Já na segunda etapa, caracterizada pelo rompimento das ligações C-C, a incorporação do GO se mostrou eficaz para a concentração de $0,25 \%$, na qual o retardamento dessa temperatura máxima de degradação foi de $4,5^{\circ} \mathrm{C}$.

A utilização do GO funcionalizado aumentou a temperatura máxima de degradação do compósito em $4,9^{\circ} \mathrm{C}$ na primeira etapa e $5,2^{\circ} \mathrm{C}$ na segunda. Os efeitos das duas concentrações desse óxido funcionalizado foram equivalentes, o que reafirma os resultados obtidos pelo FTIR-ATR.

Era esperado que o envelhecimento promovesse uma diminuição mais acentuada da temperatura máxima de degradação do encapsulante EVA, se comparada à diminuição dessa temperatura nos filmes com GO. Entretanto, na primeira etapa, a redução da temperatura de degradação dos filmes com GO foi mais acentuada que a do encapsulante EVA, que permaneceu praticamente constante após o envelhecimento. Esse resultado pode indicar que a adição do GO ao encapsulante EVA não melhorou a estabilidade térmica. Devese ressaltar que esse comportamento inesperado para a degradação do encapsulante EVA pode estar relacionado à dificuldade de se coletar uma amostra representativa desse polímero após o envelhecimento. Como mostrado anteriormente na Figura 2, a estrutura do filme do encapsulante EVA foi profundamente danificada e a amostra utilizada para análise não estava nos mesmos padrões das demais.

De maneira geral, para as amostras não envelhecidas, a adição de GO (funcionalizado com octadecilamina e não funcionalizado) proporcionou uma melhora no comportamento térmico do filme, tomando como referência a temperatura de degradação máxima. Esse resultado positivo também foi constatado pelas análises de FTIR-ATR. Já após o envelhecimento, não se percebeu uma melhora significativa decorrente da incorporação do GO.

\subsection{DSC}

As amostras foram analisadas por calorimetria exploratória diferencial antes e após envelhecimento. As amostras passaram por duas corridas de aquecimento.

A Tabela 4 compila os resultados de temperatura, entalpia de fusão e cristalinidade para a primeira corrida da análise de DSC antes do envelhecimento. Avaliando o primeiro pico, percebe-se que as entalpias de fusão das amostras com GO funcionalizado são maiores do que a entalpia para o encapsulante EVA, enquanto as entalpias de fusão das amostras com GO não funcionalizado são menores. Isso mostra que a funci- 
onalização cumpriu seu papel de melhor homogeneizar o compósito, favorecendo a formação de cristais imperfeitos, representados pelo primeiro pico.

Da mesma forma, os valores de entalpia do segundo pico, de maneira geral, foram iguais ou maiores do que a amostra do encapsulante EVA pura. Dessa maneira, o GO atuou como agente de nucleação do encapsulante EVA, o que levou à diminuição da energia para formação dos cristais mais organizados e definidos, representados pelo segundo pico [22] e, consequentemente, favoreceu a sua formação.

Tabela 4: Temperatura $\left(\mathrm{T}_{\mathrm{m}}\right)$ e entalpia de fusão $\left(\Delta \mathrm{H}_{\mathrm{m}}\right)$ da primeira corrida e cristalinidade $(\mathrm{X} c)$ das amostras antes do envelhecimento.

\begin{tabular}{|c|c|c|c|c|c|c|c|}
\hline AMOSTRAS & $\begin{array}{l}\mathrm{T}_{\mathrm{m}}{ }^{1} \\
\left({ }^{\circ} \mathrm{C}\right)\end{array}$ & $\begin{array}{l}\Delta H_{m}{ }^{1} \\
(J / g)\end{array}$ & $\begin{array}{l}\mathrm{T}_{\mathrm{m}}{ }^{2} \\
\left({ }^{\circ} \mathrm{C}\right)\end{array}$ & $\begin{array}{l}\Delta \mathbf{H}_{\mathrm{m}}{ }^{2} \\
(\mathrm{~J} / \mathrm{g})\end{array}$ & $\begin{array}{l}\mathrm{T}_{\mathrm{m}}{ }^{3} \\
\left({ }^{\circ} \mathrm{C}\right)\end{array}$ & $\begin{array}{l}\Delta \mathbf{H}_{\mathrm{m}}{ }^{3} \\
(\mathrm{~J} / \mathbf{g})\end{array}$ & $\begin{array}{l}X c \\
(\%)\end{array}$ \\
\hline EVA & 43,5 & 8,30 & 58,3 & 0,22 & 73,5 & 5,94 & 4,94 \\
\hline $0,10 \% \mathrm{~m} / \mathrm{m}$ GO & 46,6 & 6,62 & 74,0 & 11,25 & - & - & 6,10 \\
\hline $0,25 \% \mathrm{~m} / \mathrm{m}$ GO & 45,7 & 5,79 & 72,9 & 8,75 & - & - & 4,96 \\
\hline $0,10 \% \mathrm{~m} / \mathrm{m}$ GO func. & 44,2 & 9,50 & 72,0 & 11,36 & - & - & 7,12 \\
\hline $0,25 \% \mathrm{~m} / \mathrm{m}$ GO func. & 45,1 & 8,30 & 71,8 & 10,19 & - & - & 6,31 \\
\hline
\end{tabular}

Como pode ser observado na Tabela 5, na segunda corrida, a cristalinidade das amostras com $0,10 \%$ $\mathrm{m} / \mathrm{m}$ de GO (com e sem funcionalização) apresentaram maior cristalinidade quando comparadas com a amostra do encapsulante EVA. Isso provavelmente se deve à presença do óxido de grafeno, que atuaria como agente de nucleação (superfícies para criação e crescimento de cristais) o que levou à diminuição da energia para formação dos cristais e, consequentemente, favoreceu a sua formação. No entanto, ao aumentar a concentração do GO, a cristalinidade diminui. Além disto, percebe-se um efeito da funcionalização do óxido de grafeno: a diminuição da cristalinidade foi menor na amostra funcionalizada devido à melhor homogeneização dos filmes, o que pode ter favorecido o desenvolvimento da estrutura cristalina.

Tabela 5: Temperatura $\left(\mathrm{T}_{\mathrm{m}}\right)$ e entalpia de fusão $\left(\Delta \mathrm{H}_{\mathrm{m}}\right)$ e cristalinidade $\left.\mathrm{X} c\right)$ das amostras na segunda corrida de DSC antes do envelhecimento.

\begin{tabular}{c|c|c|c}
\hline AMOSTRA & $\mathbf{T}_{\mathbf{m}}\left({ }^{\circ} \mathbf{C}\right)$ & $\Delta \mathbf{H}_{\mathbf{m}}(\mathbf{J} / \mathbf{g})$ & $\mathbf{X} \mathbf{c}(\%)$ \\
\hline EVA & 72,6 & 28,72 & 9,80 \\
\hline $0,10 \% \mathrm{~m} / \mathrm{m}$ GO & 71,7 & 29,51 & 10,07 \\
\hline $0,25 \% \mathrm{~m} / \mathrm{m}$ GO & 72,9 & 23,54 & 8,03 \\
\hline $0,10 \% \mathrm{~m} / \mathrm{m}$ GO func. & 70,9 & 29,91 & 10,20 \\
\hline $0,25 \% \mathrm{~m} / \mathrm{m}$ GO func. & 72,9 & 28,1 & 9,59 \\
\hline
\end{tabular}

Para as amostras que passaram pelo processo de envelhecimento, observa-se que a quantidade de picos foi maior na amostra do encapsulante EVA, diminuindo com aumento progressivo da quantidade de GO. As amostras que apresentam $0,25 \%$ de GO apresentaram curvas parecidas às curvas antes do envelhecimento. Por isso, as análises foram feitas apenas com os resultados da segunda corrida. Os resultados da segunda corrida são mais representativos, uma vez que se eliminam os efeitos de memória térmica e possíveis resíduos de solventes [10].

As curvas de DSC referente ao segundo aquecimento das amostras envelhecidas estão apresentadas nas Figuras 12. 


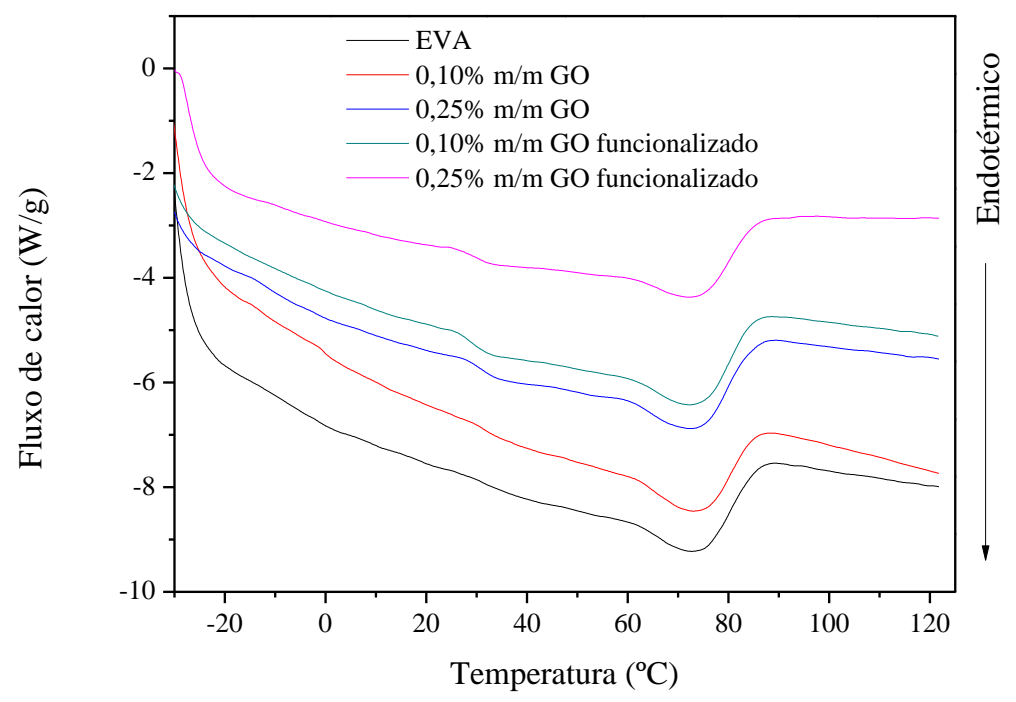

Figura 12: Segundo aquecimento das amostras do encapsulante EVA com $0,10 \%$ e $0,25 \% \mathrm{~m} / \mathrm{m}$ de óxido de grafeno sem funcionalizar e funcionalizado após o envelhecimento.

Como pode ser observado na Tabela 6, na segunda corrida, a cristalinidade das amostras aumentou à medida que a concentração de óxido de grafeno cresceu. Isso provavelmente se deu, novamente, pela presença do GO, que atuou como superfície de nucleação. O processo de degradação por envelhecimento leva à cisão das cadeias poliméricas, ocasionando à formação de moléculas menores e com maior mobilidade que atuam, também, como agentes de nucleação, o que favorece a formação de cristais [10].

Tabela 6: Temperatura $\left(\mathrm{T}_{\mathrm{m}}\right)$ e entalpia de fusão $\left(\Delta \mathrm{H}_{\mathrm{m}}\right)$ e cristalinidade $\left.\mathrm{Xc}\right)$ das amostras após tratamento de $200 \mathrm{~h}$ na câmara UVB ( $2^{\mathrm{a}}$ corrida).

\begin{tabular}{c|c|c|c}
\hline AMOSTRA & $\mathbf{T}\left({ }^{\circ} \mathbf{C}\right)$ & $\Delta \mathbf{H}_{\mathbf{m}}(\mathbf{J} / \mathbf{g})$ & $\mathbf{X} \mathbf{c}(\%)$ \\
\hline EVA & 73,08 & 28,70 & 9,80 \\
\hline $0,10 \% \mathrm{~m} / \mathrm{m} \mathrm{GO}$ & 72,38 & 30,78 & 10,50 \\
\hline $0,25 \% \mathrm{~m} / \mathrm{m}$ GO & 72,57 & 31,41 & 10,72 \\
\hline $0,10 \% \mathrm{~m} / \mathrm{m}$ GO func. & 72,06 & 28,82 & 9,84 \\
\hline $0,25 \% \mathrm{~m} / \mathrm{m}$ GO func. & 72,36 & 32,30 & 11,02 \\
\hline
\end{tabular}

Os resultados obtidos pela técnica analítica de DSC deste trabalho indicam uma eficiente funcionalização do óxido de grafeno, que gerou um nanocompósito de distribuição mais homogênea. Entretanto, como tanto o GO, quanto as cadeias menores, originárias da degradação do encapsulante EVA, diminuem o tamanho dos esferólitos, não se pode vincular os resultados de cristalinidade obtidos apenas com a degradação. As amostras não revelaram variação significativa de temperatura antes e após o envelhecimento, o que também impossibilita a conclusão, pela análise de DSC, de uma degradação preferencial das amostras que não contêm $\mathrm{GO}$

Assim sendo, o teste de calorimetria exploratória diferencial, embora tenha apresentado importantes informações quanto à estrutura dos nanocompósitos, não permitiu conclusões relacionadas à sua degradação. No entanto, comparando os resultados do DSC com os demais já apresentados, observa-se que a cristalinidade pode ter uma relação com o nível de degradação dos materiais. Ao mesmo tempo em que a cristalinidade aumentou após envelhecimento nas amostras que continham GO, concluiu-se, dos resultados da técnica FTIR-ATR, que a inserção de óxido de grafeno na matriz polimérica pode ter protegido o polímero de pro- 
cessos de degradação mais acentuados. Sendo assim, pode-se fazer uma ligação entre maior cristalinidade e menor degradação.

\section{CONCLUSÕES}

Diante da necessidade por encapsulantes mais resistentes à degradação por radiação UV, neste trabalho, concluiu-se que o GO, ainda que de forma sutil, atuou de maneira positiva no aumento da resistência à fotodegradação do EVA.

Na tentativa de melhorar a dispersão de GO no encapsulante EVA e observar melhor a degradação nas análises, buscou-se funcionalizar a superfície do GO com octadecilamina. Além disto, a utilização do ultrassom de ponta e a evaporação pelo método casting contribuíram de maneira eficiente para a dispersão do GO na matriz polimérica. É importante ressaltar que o método de evaporação casting para preparação dos filmes melhorou a dispersão de GO no encapsulante EVA, mesmo sem a funcionalização.

Através da inspeção visual foi possível constatar, aparentemente, que os filmes com a adição de GO foram menos danificados pelo processo de degradação. Corroborando com tal inspeção, por FTIR-ATR, notou-se degradação mais acentuada na amostra sem óxido de grafeno inserido na matriz polimérica, o que pode indicar que o GO atuou de forma eficiente para maior proteção do EVA frente à radiação UVB. Os resultados termogravimétricos demonstraram que a superfície do GO foi devidamente funcionalizada. De maneira geral, para as amostras não envelhecidas, a adição de GO (funcionalizado e não funcionalizado) proporcionou uma melhora no comportamento térmico do filme, tomando como referência a temperatura de degradação máxima.

Neste estudo verificou-se o aumento da cristalinidade devido à incorporação do GO, que funciona como agente de nucleação. Observou-se também um aumento da cristalinidade após a degradação devido à existência de cadeias mais curtas que funcionam, também, como agentes de nucleação. Porém, não foi possível observar variações significativas nos resultados após o processo de envelhecimento acelerado.

Dessa maneira, os resultados podem ser utilizados como ponto de partida para outros trabalhos relacionados aos nanocompósitos poliméricos de GO. Conclui-se, também, que a utilização dos nanocompósitos de EVA/GO funcionalizado como encapsulante de células fotovoltaicas seria dificilmente viável nas condições estudadas, uma vez que o óxido de grafeno reduziu sensivelmente a transmitância do filme, mesmo que em pequenas quantidades. Sugere-se o estudo da aplicação do GO com menos folhas, para alcançar a transparência desejada para um encapsulante de módulos fotovoltaicos.

Logo, este artigo mostra como avanço científico o uso da nanotecnologia, no caso o GO, como aplicação para minimizar a degradação do encapsulante para módulos fotovoltaicos. Mas ainda é preciso avançar nas pesquisas a fim de alcançar a transparência desejada para o encapsulante.

\section{AGRADECIMENTOS}

O presente trabalho foi realizado com apoio da Coordenação de Aperfeiçoamento de Pessoal de Nível Superior (CAPES). Os autores agradecem este apoio financeiro e ainda ao Conselho Nacional de Desenvolvimento Científico e Tecnológico, CNPq, e à Fundação de Amparo à Pesquisa de Minas Gerais, FAPEMIG.

\section{BIBLIOGRAFIA}

[1] KABIR, E., KUMAR, P., KUMAR, S., et al., "Solar energy: potential and future prospects", Renewable and Sustainable Energy Reviews, v. 82, pp. 894-900, Feb. 2018.

[2] BLASCHKE, T., BIBERACHER, M., GADOCHA, S., et al., "Energy landscapes: meeting energy demands and human aspirations", Biomass- Bioenergy. v. 55. pp. 3-16, Ago. 2013.

[3] OTTERSBÖCK, B., ORESKI, G., PINTER, G., "Comparison of different microclimate effects on the aging behavior of encapsulation materials used in photovoltaic modules", Polymer Degradation and Stability, v. 138, pp.182-191, Abr. 2017.

[4] OLIVEIRA, M.C.C., DINIZ, A.S.A.C., VIANA, M.M., et al., "The causes and effects of degradation of encapsulant ethylene vinyl acetate copolymer (EVA) in crystalline silicon photovoltaic modules: A review", Renewable and Sustainable Energy Reviews, v.81, pp. 2299-2317, Jan. 2018. 
[5] OLIVEIRA, M.C.C., CASSINI, D.A., DINIZ, A.S.A.C., et al., "Comparison and analysis of performance and degradation differences of crystalline-Si photovoltaic modules after 15-years of field operation", Solar Energy, v. 191, pp. 235-250, Out. 2019.

[6] OLIVEIRA, M.C.C., SOARES, L.G., VIANA, M.M., et al., "Development of ethylene-vinyl acetate copolymer/graphene oxide nanocomposites for crystalline silicon photovoltaic modules", International Journal of Adhesion and Adhesives, v.100, n. 102595, pp.1-11, Mar. 2020.

[7] NANDI, D., TALUKDAR, A., GHOSH, U.C., et al., "Reduced graphene oxide/ ethylene vinyl acetate co-polymer composite with improved thermal stability and flame retardancy", Journal of Polymer Materials, v. 29, n. 4, pp. 411-421, Out. 2012.

[8] BAHMANYAR, M., SEDAGHAT, S., AHMAD RAMAZANI, S.A., et al., "Preparation of Ethylene Vinyl Acetate Copolymer/ Graphene Oxide Nanocomposite Films via Solution Casting Method and Determination of the Mechanical Properties", Polymer-Plastics Technology and Engineering, v. 54, pp. 218-222, Jan. 2015.

[9] Astenik Solar. Innovative Renewable Energy Systems.

http://www.asteniksolar.com/products/materials/first_eva.html. Acessado em junho de 2018.

[10] JIN, J., CHEN, S., ZHANG, J., "UV aging behaviour of ethylene-vinyl acetate copolymers (EVA) with different vinyl acetate contents", Polymer Degradation and Stability, v. 95, pp. 725-732, Mai. 2010.

[11] LIU, F., JIANG, L., YANG, S., "Ultra-violet degradation behavior of polymeric backsheets for photovoltaic modules", Solar Energy, v. 108, pp. 88-100, Out. 2014.

[12] JENTSCH, A., EICHHORN, K.-J., Voit, B., "Influence of typical stabilizers on the aging behavior of EVA foils for photovoltaic applications during artificial UV-weathering", Polymer Testing, v. 44, pp. 242247, Jul. 2015.

[13] AGROUI, K., COLLINS, G., "Thermal relaxations and transitions in EVA encapsulant material during photovoltaic module encapsulation process", Materials and processes for energy: communicating current research and technological developments, Formatex Research Center, pp. 150-157, 2013. http://www.formatex.info/energymaterialsbook/book/150-157.pdf. Acessado em agosto de 2018.

[14] BADIEE, A., ASHCROFT, I.A., WILDMAN, R.D., "The thermo-mechanical degradation of ethylene vinyl acetate used as a solar panel adhesive and encapsulant", International Journal of Adhesion \& Adhesives, v. 68, pp. 212-218, Jul. 2016.

[15] HIRSCHL, CH., BIEBL-RYDLO, M., DEBIASIO, M., et al., "Determining the degree of crosslinking of ethylene vinyl acetate photovoltaic module encapsulants-A comparative study", Solar Energy Materials \& Solar Cells, v.116, pp. 203-218, Set. 2013.

[16] VALENTIM, A. C. S. et al., "Efeito da Adição de $\mathrm{TiO}_{2}$ nas Propriedades Térmicas e na Cristalinidade do Copolímero de Etileno/Acetato de Vinila", Química Nova, v. 37, n. 2, pp. 255-259, Out. 2014.

http://dx.doi.org/10.5935/0100-4042.20140044

[17] KUILA, T., KHANRA, P., MISHRA, A.K., et al., "Functionalized-graphene/ethylene vinyl acetate copolymer composites for improved mechanical and thermal properties", Polymer Testing, v. 31, pp. 282-289, Abr. 2012.

[18] LA MANTIA, F.P., MALATESTA, V., CERAULO, C., et al., "Photooxidation and photostabilization of EVA and cross-linked EVA", Polymer Testing, v. 51, pp. 6-12, Mai. 2016.

[19] MARASCHIN, T. G. Preparação de óxido de grafeno e óxido de grafeno reduzido e dispersão em matriz polimérica biodegradável. Dissertação de Mestrado (Engenharia e Tecnologia de Materiais), PUCRS, Porto Alegre, 2016.

[20] ASSAL, M.E., SHAIK, M.R., KUNIYIL, M., et al., "A highly reduced graphene oxide $/ \mathrm{ZrO}_{\mathrm{x}}-\mathrm{MnCO}_{3}$ or $-\mathrm{Mn}_{2} \mathrm{O}_{3}$ nanocomposite as an efficient catalyst for selective aerial oxidation of benzylic alcohols", RSC Adv. 7, 55336-55349, Dez. 2017.

[21] WANG, C., LIU, Z., WANG, S., et al., "Preparation and properties of octadecylamine modified graphene oxide/styrene-butadiene rubber composites through an improved melt compounding method", Journal of Applied Polymer Science, n. 133, pp. 42907 (1-9), Set. 2016.

[22] AGROUI, K., COLLINS, G., "Determination of thermal properties of crosslinked EVA encapsulant material in outdoor exposure by TSC and DSC methods", Renewable Energy, v. 63, pp. 741-746, Mar. 2014. 


\section{ORCID}

Michele Cândida Carvalho de Oliveira Marcelo Machado Viana

Vanessa de Freitas Cunha Lins http://orcid.org/0000-0002-6326-9723

http://orcid.org/0000-0002-6682-2504

https://orcid.org/0000-0002-6357-9553 